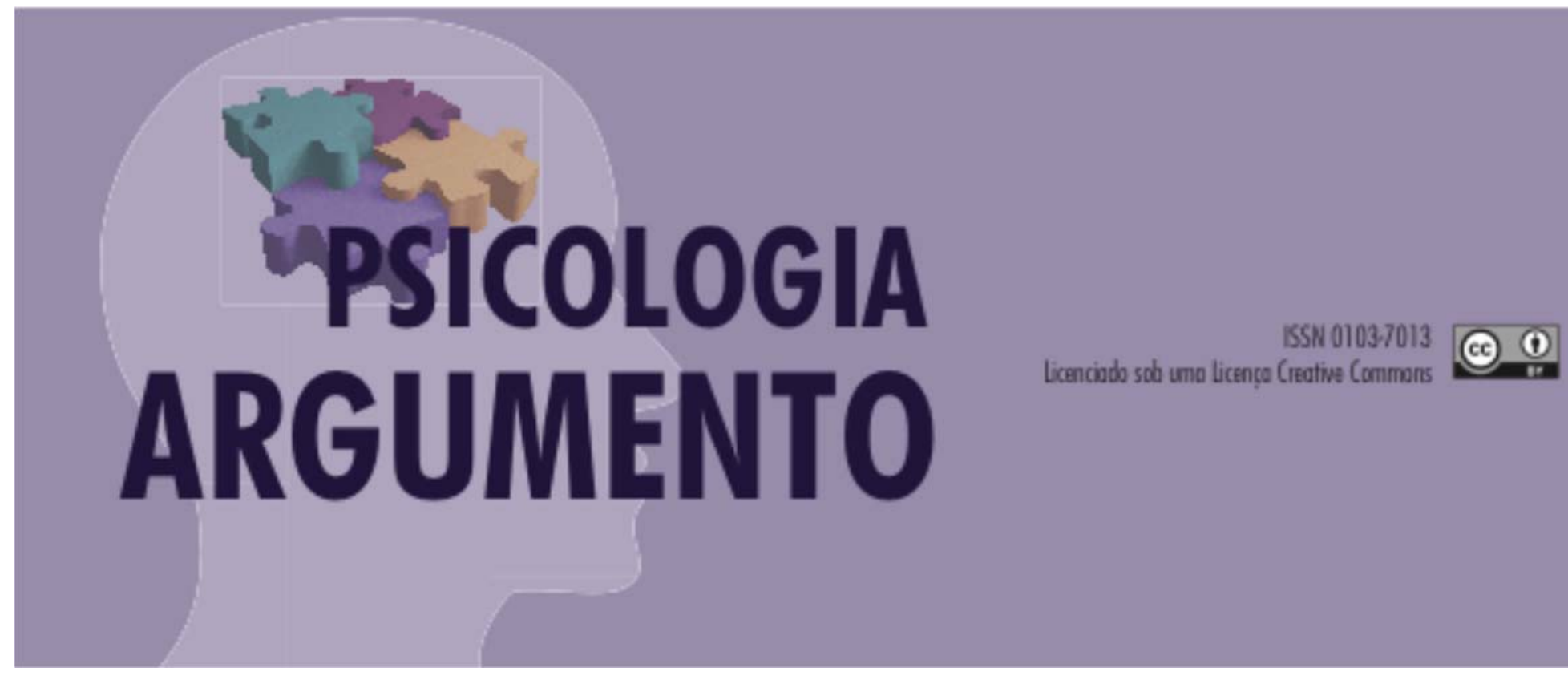

doi: http://dx.doi.org/10.7213/psicolargum.36.94.AO05

\title{
A (nova) relação pai-filhos: uma revisão integrativa da literatura nacional entre 2000 e 2019
}

\section{The (new) father-children relation: an integrative review of national literature between 2000 and 2019}

\footnotetext{
Ângela Roos Campeol

Doutoranda. Programa de Pós-Graduação em Psicologia. Universidade Federal de Santa Catarina (UFSC). Florianópolis, SC, Brasil. E-mail: angela.r.campeol@gmail.com

Maria Aparecida Crepaldi

Doutora Docente. Programa de Pós-Graduação em Psicologia. Universidade Federal de Santa Catarina (UFSC), Florianópolis, SC, Brasil. E-mail: maria.crepaldi@ufsc.br
}

\section{Resumo}

Este estudo tem como propósito apresentar uma revisão integrativa de pesquisas empíricas e nacionais acerca das relações que envolvem o pai e os filhos de 0 a 12 anos, publicados entre 2000 e 2019 em revistas brasileiras. Utilizou-se como descritores "paternidade", "relação pai-criança” e "criança”, em buscas realizadas nas bases SciELO, PePSIC e IndexPsi. Foram analisados 48 artigos. Os resultados foram submetidos à Análise de Conteúdo e à análise de frequência simples, apresentados a partir das seguintes categorias: (1) Ano de publicação, (2) Método de Pesquisa, (3) Principais resultados. Destacase a relevância desse estudo para o progresso do conhecimento científico referente ao tema, ao atentar para complexidade dos fatores que perpassam a relação entre o pai e as crianças. Além disso, o estudo pode contribuir para a visibilidade da função paterna no sistema familiar, bem como para consolidação de políticas públicas que reconheçam a importância paterna para o desenvolvimento dos filhos.

Palavras-chave: Pai; Paternidade; Relação pai-criança. 


\begin{abstract}
This study aims to present an integrative review of empirical and national research on the relation involving the father and children from 0 to 12 years old, published between 2000 and 2019 in Brazilian journals. The descriptors "fatherhood", "father-child relation" an "child" were used in searches carried out at the SciELO, PePSIC and IndexPsi databases. Forty-eight articles were analyzed. The results were submitted to Content Analysis and simple frequency analysis, presented from the following categories: (1) Year of publication, (2) Research Method, (3) Main results. Considering the complexity of factors that permeate the relation between father and children, it can be highlighted the relevance of this study to the progress of scientific knowledge regarding this topic. In addition, it contributes to the visibility of paternal role in the family system, as well as to consolidate public policies that recognize the paternal importance for children's development.
\end{abstract}

Keywords: Father; Fatherhood; Father-child relation.

\title{
Resumen
}

El objetivo de este estudio es presentar una revisión integradora de la investigación empírica y nacional sobre las relaciones entre padres e hijos de 0 a 12 años, publicada entre 2000 y 2019 en revistas brasileñas. Los descriptores utilizados fueron "paternidad", "relación padre-hijo" e "hijo" en 48 artículos. Las búsquedas se realizaron en las bases de datos SciELO, PePSIC e IndexPsi . Los resultados fueron sometidos a Análisis de Contenido y análisis de frecuencia simple, presentados en las siguientes categorías: (1) Año de publicación, (2) Método de Investigación, (3) Resultados Principales. Se enfatiza la relevancia de este estudio para el progreso del conocimiento científico sobre el tema, al considerar la complejidad de los factores que impregnan la relación entre el padre y los hijos. Además, este estudio puede contribuir a la visibilidad de la función paterna en el sistema familiar, así como a la consolidación de políticas públicas que reconozcan la importancia paterna para el desarrollo de los niños.

Palabras llave: Padre; Paternidad; Relación padre-hijo.

\section{Introdução}

O interesse em compreender a influência paterna para o desenvolvimento infantil emergiu no contexto científico, na contemporaneidade, fomentado por uma série de transformações sociais. A partir da década de 1970, a ascensão do modelo econômico industrial e do movimento feminista, os questionamentos das desigualdades de gênero, o avanço dos métodos contraceptivos e a inserção das mulheres no mercado de trabalho repercutiram em novas expectativas, crenças e atitudes sobre as funções de pai e mãe (Cabrera, Tamis-LeMonda, Bradley, Hofferth, \& Lamb, 2000; Staudt \& Wagner, 2008).

As publicações, ao longo do tempo, mostram-se consistentes em promover a análise do exercício da maternidade, e a qualidade da relação mãe-criança tem sido reconhecida como fundamental para o desenvolvimento humano. Enquanto isso, o fazer da paternidade ainda não 
é igualmente compreendido pelas ciências humanas e da saúde no Brasil. Entretanto, considerase que houve, nas últimas décadas, um crescente interesse da ciência psicológica pela função paterna, e os estudos sinalizam a necessidade de ampliar as pesquisas na área (Bossardi \& Vieira, 2015; Bueno, Gomes, \& Crepaldi, 2015).

A participação do pai para promover o desenvolvimento infantil começou a ser evidenciada, a partir da publicação do livro O Papel do pai no desenvolvimento infantil, pelo americano Michael E. Lamb, em 1979. No Brasil, os estudos sobre homens e masculinidades têm como marco a Conferência Internacional sobre Populações e Desenvolvimento, das Nações Unidas, em 1994. Nesta ocasião, intensificou-se a necessidade de incluir os homens na vida familiar e equilibrar as relações de poder entre os gêneros. De acordo com a revisão da literatura referente ao modo como a paternidade vem sendo compreendida no Brasil, organizada por Oliveira e Silva (2011), registrou-se no país um significativo crescimento, a partir de 2004, no número de estudos referentes ao pai.

Ao fazer o exercício de ampliar o olhar sobre o fenômeno da paternidade, há o reconhecimento de que a participação paterna nos cuidados à criança implicou em um contínuo processo de superação do modelo exclusivamente materno. Este importante movimento pode sinalizar o processo de transição da paternidade, em que o homem vem assumindo uma nova postura parental. Observa-se que o homem-pai está se distanciando da função unicamente de provedor da família e aproximando-se de uma figura afetiva e de cuidado (Bossardi \& Vieira, 2015). Nesse contexto, ao mesmo tempo em que se faz presente o conceito de "novo pai", subsistem no imaginário social caraterísticas do "antigo pai”, associadas a uma concepção tradicional de paternidade (Staudt \& Wagner, 2008; Oliveira \& Silva, 2011). De todo modo, os estudos atuais, com interesse em compreender a influência paterna nas relações familiares, mostram-se convergentes ao afirmar a relevância da participação do pai para o desenvolvimento saudável dos filhos (Cabrera, et al, 200; Souza \& Benetti, 2008; Vieira, et al, 2014; Bossardi \& Vieira, 2015; Bueno; Gomes \& Crepaldi, 2015).

Dentre as contribuições científicas para melhor compreender a paternidade, despontou uma série de conceitos para discutir a participação do pai no desenvolvimento infantil. Dentre as principais nomenclaturas aparecem: investimento, engajamento e envolvimento paterno. A definição mais difundida é a de envolvimento paterno, proposta por Lamb e sua equipe, em 1985, que inclui três dimensões fundamentais: interação, disponibilidade e responsabilidade 
(Lamb, Pleck, Charnov, \& Levine, 1985). A interação refere-se à experiência do pai em contato direto com a criança em cuidados e atividades compartilhadas. A disponibilidade diz respeito a acessibilidade física e/ou psicológica do pai em relação a criança, o que favorece a ocorrência de interações entre a díade. A responsabilidade corresponde às tarefas ligadas aos cuidados e recursos destinados para a criança, além de preocupações, planejamento e organizações assumidas pelo pai, que não demandam interação direta (Lamb, 2000; Lamb, Pleck, Charnov, \& Levine, 1985).

Além disso, as investigações atuais indicam que o pai exerce uma função específica na socialização e no controle da agressividade, principalmente durante a primeira infância (Cabrera, et al., 2000; Paquete, 2004, Bueno, Gomes, \& Crepaldi, 2015). Essa função é representada pela Teoria da Relação da Ativação, que sugere que a relação de ativação representa o vínculo afetivo que a criança desenvolve com o pai que realiza com ela a abertura ao mundo (Paquette, 2004). Em uma relação de ativação satisfatória, enquanto o pai realiza brincadeiras físicas com os filhos, ele incentiva as crianças a tomarem iniciativa, a explorar, se aventurar e enfrentar obstáculos, ou seja, a criança aprende a ter confiança em suas capacidades e autonomia para enfrentar as situações, em um contexto de segurança proporcionado pelo pai (Dumont \& Paquette, 2012). Por exemplo, os jogos de luta ou de batalha podem promover a regulação da emoção, disciplina e a obediência, habilidades sociais essas que facilitam as relações com o ambiente externo.

Considerando a família como o principal contexto para o desenvolvimento das crianças e a contribuição paterna nesse processo, este trabalho de revisão integrativa da literatura empírica e nacional, propõe discutir algumas questões sobre as relações que envolvem o pai e os filhos de 0 a 12 anos. Cabe salientar que este estudo visa proporcionar uma descrição do cenário atual, a partir da qual seja possível identificar os principais temas estudados, suas contribuições e contradições, bem como as lacunas ainda existentes na produção científica nacional.

\section{Método}

Realizou-se uma revisão integrativa da literatura, a partir do levantamento da produção científica nacional sobre a relação pai-criança. A construção do estudo esteve pautada nas cinco etapas propostas por Mendes, Silveira e Galvão (2008): (1) escolha/definição do tema ou elaboração da questão de pesquisa; (2) estabelecimento de critérios de inclusão e exclusão de 
estudos ou busca na literatura (amostragem); (3) definição de critérios para categorização dos estudos; (4) avaliação dos estudos incluídos na revisão integrativa; (5) Discussão dos resultados e, (6) apresentação da revisão integrativa. Nesse cenário, a revisão integrativa, como método de pesquisa, oportuniza uma síntese do conhecimento e a incorporação de resultados de pesquisa na prática (Creswell, 2007).

Os descritores, considerados de acordo para mapear os estudos, foram consultados no sítio dos Descritores em Ciências da Saúde (DeCS), da BVS. Os termos indexados selecionados foram: "paternidade”, "relação pai-criança” e “criança”, utilizados durante as buscas realizadas nas seguintes bases de dados: The Scientific Eletronic Library Online (SciELO), Periódicos Eletrônicos de Psicologia (PePSIC) e Index Psi Revistas Técnico-Científicas (IndexPsi). Os boleanos AND e OR foram empregados para efetuar o rastreamento de artigos.

A busca do material ocorreu no mês de junho e atualizada em agosto de 2019. Como critérios de inclusão, pautou-se em: estudos empíricos acerca da relação entre o pai e criança, com idades entre 0 e 12 anos, publicados entre os anos de 2000 e 2019 em revistas brasileiras, com texto completo disponível e em português. Ocorreu a exclusão dos estudos duplicados nas bases de dados, com discussões teóricas e que não apresentavam resultados centrais acerca da relação pai-criança no contexto brasileiro.

Desse modo, os artigos selecionados para análise foram classificados com relação a: ano de publicação, participantes, método de pesquisa e principais resultados. Os itens (1), (2) e (3) geraram dados quantitativos, submetidos à análise de frequência simples de ocorrência. O último item (4) foi organizado por similaridade dos assuntos abordados e submetido à análise qualitativa de conteúdo (Bardin, 2006), com o objetivo de conhecer os principais temas investigados e os resultados encontrados sobre a relação pai-criança. A análise gerou as seguintes categorias: A participação paterna ao longo do desenvolvimento da criança; A relação pai-criança em diferentes contextos familiares e sociais; A construção da relação pai-criança: da gestação ao puerpério; Fatores que influenciam a relação pai-criança; Percepções sobre a paternidade e; Ser pai em situação de hospitalização e necessidades especiais dos filhos.

\section{Resultados}

A revisão da literatura permitiu a localização de 178 obras, sendo 49 na base da dados SciELO, 24 no PePSIC e 105 no IndexPsi. Após uma primeira avaliação foram selecionados 
para leitura minuciosa e integral 79 publicações. Destas, foram desconsiderados 31 artigos por não apresentarem informações específicas acerca da relação pai-criança no contexto nacional. Dessa forma, as análises correspondem a 48 artigos empíricos e as categorias de análise serão apresentadas a seguir.

Ano de publicação

Destaca-se 2009 e 2018 como os anos que apresentaram o maior número de publicações referentes a relação pai-criança, com cinco artigos vinculados em cada ano (10\%). Após, os anos de 2011, 2012, 2014, 2016, 2017 contabilizaram quatro artigos veiculados em cada ano (8\% cada), seguidos de 2006 e 2013 quando foram registradas três publicações sobre a temática em cada ano (7\% cada). Os anos de 2004, 2007 e 2008 somaram duas produções em cada ano (4\% cada). A busca referente aos oito primeiros meses de 2019 também localizou duas publicações (4\%). Enquanto 2002, 2003, 2005, 2010 e 2015 tiveram uma publicação por ano (2\% cada).

\section{Participantes}

Com relação aos participantes, entre os 48 estudos analisados, em 34 o pai foi o principal respondente (71\%). Destaca-se que o pai e a mãe foram acessados em cinco estudos (10\%), e o pai e os filhos(as) participaram de três (7\%). Também, houve diversa variação entre os participantes, considerando que a coleta de informações ocorreu com o pai, a mãe e os filhos (2\%), a mãe e os filhos (2\%), apenas os filhos (2\%), o pai e os professores (2\%), o pai, a mãe e os professores (2\%) e pessoas sem filhos (2\%).

\section{Método de pesquisa}

A respeito do método empregado nos 48 artigos empíricos incluídos nesta revisão, a ampla maioria foi composta por estudos qualitativos, o que representou 34 estudos (71\%), enquanto 12 (25\%) continham informações quantitativas e dois (4\%) empregou análise quantiqualitativa. Dentre esses, 43 eram de natureza transversal (90\%) e, estudos de caráter longitudinal somaram cinco (10\%).

\section{Instrumentos}


O instrumento mais utilizado para levantamento de dados foi a entrevista (estruturada e semiestruturada), contabilizando 30 estudos (63\%), questionários foram empregados em oito trabalhos (17\%), entrevista e questionários em quatro (8\%). Observação e entrevista foram usadas em conjunto para acessar o fenômeno em três trabalhos (6\%), observação, questionário e teste, entrevista e a hora do jogo diagnóstica em um artigo cada (2\% cada).

Temas investigados e Principais Resultados

Para a apresentação dos principais resultados dos estudos foram construídas categorias temáticas, conforme a proximidade dos temas abordados pelos artigos, e serão discutidos, a seguir, de modo articulado.

A Tabela 1 traz os temas abarcados em cada uma das categorias e a respectiva porcentagem de estudos pertencente.

Tabela 1- Categorias temáticas dos estudos

\begin{tabular}{|c|c|c|}
\hline ASSUNTO & TEMAS & PORCENTAGEM \\
\hline $\begin{array}{l}\text { A participação paterna } \\
\text { ao longo do } \\
\text { desenvolvimento da } \\
\text { criança }\end{array}$ & $\begin{array}{l}\text { O desempenho da paternidade e sua } \\
\text { influência em diferentes etapas do } \\
\text { desenvolvimento dos filhos }\end{array}$ & $23 \%$ \\
\hline $\begin{array}{l}\text { A relação pai-criança } \\
\text { em diferentes contextos } \\
\text { familiares e sociais }\end{array}$ & $\begin{array}{l}\text { Separação conjugal, } \\
\text { monoparentalidade, adoção, } \\
\text { reprodução humana assistida, } \\
\text { famílias de camadas médias e } \\
\text { populares }\end{array}$ & $21 \%$ \\
\hline $\begin{array}{l}\text { A construção da relação } \\
\text { pai-criança: da gestação } \\
\text { ao puerpério }\end{array}$ & $\begin{array}{c}\text { Participação paterna durante } \\
\text { gestação, parto, amamentação e } \\
\text { puerpério }\end{array}$ & $17 \%$ \\
\hline $\begin{array}{l}\text { Fatores que influenciam } \\
\text { a relação pai-criança }\end{array}$ & $\begin{array}{l}\text { Variáveis que interferem no } \\
\text { exercício da paternidade }\end{array}$ & $17 \%$ \\
\hline $\begin{array}{l}\text { Percepções sobre a } \\
\text { paternidade }\end{array}$ & $\begin{array}{l}\text { Concepções sobre paternidade na } \\
\text { perspectiva de pais, mães e pessoas } \\
\text { sem filhos }\end{array}$ & $12 \%$ \\
\hline $\begin{array}{l}\text { Ser pai em situação de } \\
\text { hospitalização e } \\
\text { necessidades especiais } \\
\text { dos filhos }\end{array}$ & $\begin{array}{l}\text { Pais de filhos com alguma } \\
\text { deficiência e hospitalizados }\end{array}$ & $10 \%$ \\
\hline
\end{tabular}


A participação paterna ao longo do desenvolvimento da criança

Englobam esta categoria onze estudos acerca do desempenho da paternidade e a sua inter-relação com características socioemocionais, cognitivas e comportamentais de suas crianças. Destes, sete trabalhos discutiram especificamente o envolvimento e/ou a experiência paterna em diferentes etapas do desenvolvimento: aos três meses de vida do bebê, durante o primeiro ano, aos dois anos de idade e durante os três primeiros anos da criança. A repercussão do exercício paterno para o desenvolvimento de atividades escolares dos filhos envolveu dois estudos, e duas publicações discutiram a relação entre o envolvimento paterno e os problemas externalizantes na infância.

Os resultados empíricos a respeito do envolvimento paterno evidenciaram sentimentos positivos em relação à prole e o desejo de maior participação na vida familiar (Gonçalves, Guimarães, Silva, Lopes, \& Piccinini, 2012). Contudo, os homens consideravam a sua participação restrita, principalmente, em função das questões impostas pelo trabalho (Piccinini, Silva, Gonçalves, Lopes, \& Tudge, 2012). Na primeira infância, o envolvimento dos pais esteve voltado para atividades lúdicas mais do que para os cuidados físicos das crianças (Castoldi, Gonçalves, \& Lopes, 2014), quando apareceram sentimentos de incompetência e insegurança diante dos cuidados com os filhos (Gabriel, Silva, Portugal, \& Piccinini, 2015; Polli, Gabriel, Piccinini, \& Lopes, 2016), e a preocupação com o estado emocional da mãe e com a sua sobrecarga (Gabriel, et al., 2015). À medida que aumenta a idade das crianças os resultados revelaram maior envolvimento do pai no cotidiano dos filhos, estimulando novas potencialidades, entre elas a de maior autonomia (Seabra \& Seidl-de-Moura, 2011; Gabriel, Polli, Dall’ Agnol, Tudge, \& Piccinini, 2016).

Em crianças com idade escolar, observou-se que quanto maior a frequência de comunicação e participação do pai nas atividades escolares, culturais e de lazer dos filhos maiores são os níveis de comportamentos adequados e o repertório de habilidades sociais nas crianças, enquanto o índice de hiperatividade mantém-se baixo (Cia \& Barham, 2009), o que favorece o desempenho acadêmico (Cia, D’Affonseca, \& Barham, 2004). Em consonância, os estudos sobre comportamentos agressivos das crianças sinalizam que pais envolvidos com os seus filhos tendem a realizar mais atividades de suporte emocional, disciplina e jogos físicos, o que se encontra associado ao fato dos filhos apresentam menos problemas de externalização 
(Gomes, Crepaldi, \& Brigas, 2013). Por sua vez, correlações positivas foram encontradas entre práticas paternas negativas e os problemas externalizantes dos filhos (Freitas \& Alvarenga, 2016).

A relação pai-criança em diferentes contextos familiares e socias

Esta categoria comporta dez estudos, dos quais, oito abordaram a relação pai-criança estabelecida em arranjos familiares não tradicionais e dois em contextos sociais diversos. A respeito das diferentes configurações familiares, quatro publicações discutiram a experiência da paternidade a partir da separação conjugal. Dois estudos investigaram a paternidade diante da infertilidade e do desejo de concretização e continuidade da família com a chegada de um filho, a partir da adoção e da reprodução humana assistida (RHA). Outro estudo investigou a monoparentalidade masculina e, o último dentre os estudos que trataram dos arranjos familiares, objetivou compreender a função paterna em diferentes configurações de famílias associando suas vivencias ao desenvolvimento emocional das filhas. Já os estudos que incluíram os contextos sociais, envolveram pais/homens de camadas médias e de camadas populares da sociedade.

A respeito das vivências referentes à separação conjugal, os relatos dos pais indicaram o desejo de manter com os filhos uma relação de proximidade e afeto, apesar do distanciamento gerado pelo desenlace matrimonial (Souza, Smeha, \& Arend, 2012). Interações conflitantes com a mãe das crianças mostraram-se desvantajosas para a relação pai e filho (Warpechowski \& Mosmann, 2012), apontando para dificuldades em estabelecer um vínculo afetivo entre eles devido aos efeitos da dissolução conjugal (Cúnico, Arpini, \& Cantele, 2013; Cúnico \& Arpini, 2014).

As investigações sobre o desejo da paternidade diante da infertilidade, evidenciaram que essa situação pode ocasionar sofrimento e algumas resistências no homens, devido a culpabilização pela impossibilidade ser pai de forma natural/tradicional (Haslinger e Bottoli, 2017) e o sentimento de angústia pela expectativa da chegada do filho (Bueno, Vieira, \& Crepaldi, 2016). Também é possível destacar que, para os pais, não havia diferença em seus sentimentos em relação aos filhos pelo fato de serem adotivos (Bueno, Vieira, \& Crepaldi, 2016) e que, independentemente da paternidade ser possível por meio da RHA ou de forma 
tradicional, trouxe inúmeras redefinições, novas atribuições e desafios diante da nova função a ser desempenhada (Haslinger e Bottoli, 2017).

No contexto da monoparentalidade masculina, os cuidados paternos revelaram-se ativos e permeados por afeto e preocupação de estar presente de modo integral na vida dos filhos. A respeito das dificuldades e preocupações enfrentadas, os pais acreditavam que estas estariam relacionadas à fase em que os filhos encontravam, independente da configuração familiar (Denardi \& Bottoli, 2017). Nesse sentido, o estudo de Scaglia, Mishima-Gomes e Barbieri (2018), confirmou que a constituição familiar da díade pai-criança parece não ser o fator que mais interfere na relação paterna com os filhos, questões como a influência materna e da família extensa, a valorização do provimento financeiro, a dificuldade diante da expressão do afeto e conflito com "antigas” e "novas” demandas paternas estariam mais direta ou indiretamente associadas com o relacionamento paterno-filial.

Ao ampliar o entendimento da relação pai-criança para os contextos sociais, os estudos em famílias de camadas médias indicaram certas mudanças no comportamento paterno, principalmente em relação a maior proximidade da prole, embora o homem mantivesse como figura de autoridade (Romanelli, 2004). Já em relação ao pai do subúrbio, identificou-se que a relação afetiva com os filhos estava diretamente associada com o status de provedor, e que os cuidados físicos com as crianças tendiam a ser negados, por serem considerados atribuições femininas (Bustamante, 2005).

\subsection{A construção da relação pai-criança: da gestação ao puerpério}

Nesta sessão foram incluídos oito estudos, que abordaram a relação paterna com o bebê no período da gestação, no parto, durante o processo de amamentação, nas ações de cuidado durante o puerpério, e a experiência subjetiva.

No período gestacional, os resultados dos estudos mostraram que os pais estiveram conectados à gestante e ao bebê (Piccinini, Silva, Gonçalves, Lopes, \& Tudge, 2004), de modo que, verificou-se a existência de uma expressiva disponibilidade dos pais nesse período, tanto em termos emocionais como comportamentais (Krob, Piccinini, \& Silva, 2009; Piccinini, Levandowski, Gomes, Lindenmeyer, \& Lopes, 2009). Embora, também se tenha registrado que alguns homens encontraram resistências em perceber o filho como real e estabelecer um vínculo emocional com a gestação (Piccinini, et al., 2004). 
Em relação a participação do paterna no momento do parto, os participantes sinalizaram que a experiência foi considerada um momento especial e impactante. Além disso, o acompanhamento do nascimento foi assimilado como fundamental para a construção do vínculo pai-filho (Oliveira \& Silva, 2012). O estudo acerca do processo de amamentação, evidenciou que o comportamento dos homens e das mulheres se volta para a exclusão do pai desse momento, devido a um valor cultural centrado no corpo biológico que amamentar pertence exclusivamente às mulheres (Pontes, Alexandrino, \& Osório, 2008). Acerca do período puerperal, os pais ressaltaram a responsabilidade aumentada após o nascimento, principalmente em relação ao aspecto financeiro. Sendo que, consideravam que o período de licençapaternidade não cobria a necessidade de estar próximo na esposa e do filho (Oliveira \& Brito, 2009). Nesse sentido, o tornar-se pai esteve associado a um reposicionamento de atividades, reorganização dos horários dedicados aos interesses pessoais e mudanças na relação conjugal a fim de dar conta das demandas do bebê (Cherer, Ferrari, \& Piccinini, 2018). Também, observou-se que o pai contemporâneo tem ao seu dispor um modelo de paternidade em construção, balizado pelo afeto, ao mesmo tempo em que se apropria de referenciais patriarcais ainda presentes dentro do paradigma de família (Santos \& Antúnez, 2017)

Fatores que influenciam a relação pai-criança

Oito artigos compõem a presente categoria, que trata de variáveis que interferem na relação entre pai e filhos. Entre os estudos, dois tomaram com referência características pessoais do pai e seis estudos referiam-se à aspectos contextuais, tanto familiar, como social.

Ao considerar as características pessoais do pai, a idade não se mostrou como um fator determinante para a responsividade paterna, ao comparar a interação pai-bebê entre adolescentes e adultos (Levandowski \& Piccinini, 2002). Do mesmo modo, a personalidade do homem, apesar de ser relevante na prestação de cuidados ao bebê, não se apresentou como a principal influência para interação (Afonseca, Martins, \& Pires, 2011). Nesse sentido, fatores contextuais parecem ter mais impacto sobre as relações familiares, uma vez que, o baixo envolvimento paterno com o lactente pode ser explicado pela falta de envolvimento da mãe em trabalho externo ao lar e pelo fato do casal conjugal apresentar problemas graves no seu relacionamento (Falceto, Fernandes, Baratojo, \& Giugliani, 2008). Em consonância, o estudo de Backes, Becker,Crepaldi e Vieira (2018) apontou como fatores que repercutem no 
envolvimento paterno: a relação paterna que os homens tiveram com seus próprios pais, a relação estabelecida com a mãe da criança e a rede de apoio que possuem.

Os resultados também apontaram que as condições de trabalho do pai configuram-se como uma variável de grande influência para o relacionamento pai-filho (Cia \& Barham, 2006), sugerindo que aspectos de trabalho atingem indiretamente o relacionamento entre pai e filho e diretamente a satisfação do pai a respeito do seu desempenho familiar. Nesse sentido, o estudo de Gabriel e Lopes (2016) observou que o tempo que o bebê fica na creche e o desenvolvimento deste favorecem o retorno do pai às suas atividades pessoais, em especial ao trabalho, que tem papel central na identidade do homem, e o (re)investimento na relação conjugal.

Situações de encarceramento dos pais e o reconhecimento tardio da paternidade também foram investigadas como variáveis de impacto (Ledel, Razera, Haak, \& Falcke, 2018; Palmeira \& Scorsolini-Comin, 2018). Os resultados indicaram que o aprisionamento da figura paterna gera consequências na interação com os filhos, em especial, devido ao distanciamento físico, a carência emocional e aspectos de ordem financeira (Ledel, et al., 2018). Em relação ao reconhecimento legal da paternidade, apesar de alcançado, percebeu-se que não equivale ao estabelecimento de um vínculo afetivo, promovendo a valorização da figura materna e busca por outros modelos de paternidade (Palmeira \& Scorsolini-Comin, 2018).

Percepções sobre a paternidade

Desta categoria fazem parte seis artigos que exploraram diferentes concepções sobre paternidade. Quatro dizem respeito a perspectiva dos próprios pais, um de pais e mães e um de pessoas sem filhos.

Na perspectiva dos homens, ressalta-se que estes consideravam muito importante sua participação na vida dos filhos e mostravam-se satisfeitos com o exercício da paternidade (Silva \& Piccinini, 2007), além de mencionarem perceber diferenças e semelhanças em relação ao próprio pai no modo de exercer a paternidade (Gabriel \& Dias, 2011). Os pais relataram dividir com as esposas as responsabilidades pelas crianças (Silva \& Piccinini, 2007) e estar envolvidos com as tarefas de cuidado e preocupados com a educação e a saúde dos filhos. Destaca-se que os pais que eram participativos no cotidiano da prole valorizam a confiança, a segurança e a proximidade como necessidades fundamentais para as crianças, bem como, priorizam momentos para ouvir e conversar com estes (Silva, Bueno, \& Ribeiro, 2014). Em contrapartida, 
o estudo de Jager e Bottoli (2011) apontou que, com a chegada de um bebê, os homens perceberam um distanciamento afetivo entre o casal e que, dentre as responsabilidades masculinas, sobressaia-se o desempenho do papel de provedor, já que os cuidados diretos com o bebê eram perpassados por questões de gênero.

A partir do ponto de vista de pais e mães não foram encontradas diferenças significativas entre as concepções destes referentes ao comportamento paterno ideal, no entanto, a respeito da paternidade dita real, os homens avaliaram sua participação mais efetiva do que no entendimento das mães (Prado, Piovanotti, \& Vieira, 2007). Já na percepção de pessoas sem filhos, a respeito da função paterna de abertura ao mundo, as análises estatísticas apontaram que a concepção social que prevalece é que o pai ativa meninos com intensidade maior do que ativa meninas (Paraventi, Bittencourt, Schulz, Souza, Bueno, \& Vieira, 2017).

Ser pai em situação de hospitalização e necessidades especiais dos filhos

Integram esta categoria cinco artigos acerca das vivências de pais de filhos com necessidades especiais ou com a experiência de hospitalização. Quatro estudos abordaram questões de deficiência dos filhos, como Síndrome de Down, deficiência auditiva, deficiência mental e microcefalia. Enquanto uma publicação envolveu o contexto de cuidados hospitalares de um filho prematuro.

Em casos de deficiência os resultados revelaram o impacto do diagnóstico e as dificuldades emocionais enfrentadas pelos pais (Canho, Neme, \& Yamanda, 2006). Superado esse momento, os pais reconheciam-se como participativos no desempenho de atividade e cuidados direcionados aos filhos, embora o tempo disponível fosse considerado restrito em função do trabalho (Henn \& Piccinini, 2010). Todavia, observaram-se ambientes domiciliares marcados por papeis tradicionais e pouca estimulação paterna às crianças (Silva \& Aielo, 2009). Uma vez que, apesar do engajamento em atividades de brincar e participação social, os pais atuavam como auxiliares das mães nos cuidados diários com os filhos (Cruz, Santos, Silva, Reis, \& Silva, 2019). Situações que envolvem hospitalização da criança, como no caso da prematuridade, chamaram a atenção para o sofrimento vivido pelos pais no período de internação, marcado pelo sentimento de incompletude ao deixar o filho no hospital, por movimentos de solidariedade de pessoas próximas e aprendizagens de cuidar do filho e assumir responsabilidades paternas nesse contexto (Tronchin \&Tsunechiro, 2006). 


\section{Discussão}

O exercício da paternidade tem se modificado e, nesse contexto, o crescente número de publicações com interesse no tema é reflexo da maior visibilidade, da sociedade contemporânea, na participação do pai na vida dos filhos (Souza \& Benetti, 2008). A despeito da relevância do tema, ainda são considerados poucos os estudos nacionais na área, quando comparados aos estudos internacionais. A temática da paternidade, em especial a influência paterna na vida dos filhos, apresenta-se com um vasto campo que merece ser mais bem compreendido como um processo complexo e pluridimensional.

A escolha de buscar artigos a partir do ano 2000, deveu-se ao crescente interesse em investigar a paternidade e o papel masculino, no âmbito da psicologia, em razão das inegáveis transformações sociais, impulsionadas no final do século XX (Souza \& Benetti, 2009). Entretanto, nenhum artigo empírico nacional, envolvendo a relação pai-criança, foi encontrado anteriormente a 2002. Contudo, observou-se, a partir dessa data, um interesse contínuo das investigações, especialmente, a partir de 2009.

A respeito da metodologia apresentada nos estudos analisados, chama-se a atenção para prevalência da abordagem qualitativa. Como decorrência dessa escolha, houve uma preferência por entrevistas, para o levantamento de dados, sendo este o instrumento de pesquisa mais utilizado, seja de modo isolado ou em associação com outras técnicas. Estes dados permitem pensar que as pesquisas desenvolvidas até o momento exploram mais os fenômenos de modo particularizado e em profundidade. Visto que, as pesquisas qualitativas privilegiam dar vazão aos sentimentos, expectativas e percepções dos homens a respeito da sua experiência com os filhos. Todavia, já se considera expressivo o número de estudos de cunho quantitativo, embora, esta abordagem ainda instigue novas investigações, já que se mostra importante para compreender os fenômenos de forma mais ampla.

Além disso, observou-se a necessidade de as pesquisas brasileiras investirem em estudos longitudinais, uma vez que, os recortes transversais predominaram entre os estudos. Há o reconhecimento de que investigações longitudinais demandam investimento financeiro, de tempo e de recursos humanos envolvidos com a pesquisa, porém, a realização desses estudos é de grande relevância para obter-se avanços na compreensão da complexidade de variáveis com efeitos na relação pai-criança. 
Em termos da inclusão de participantes, destaca-se que os homens foram os principais informantes sobre a relação estabelecida com os filhos, o que representa a preocupação dos pesquisadores frente a importância do discurso do pai a respeito de suas vivências. O que revela, ainda, grande avanço científico, uma vez que, a prática comum era buscar entender a paternidade através de outros informantes, geralmente a mãe ou a criança.

Acerca das categorias temáticas, em especial a respeito dos cuidados paternos direcionados aos filhos, destaca-se que a "condição" de pai vem se transformando e significativos avanços são retratados nas atividades de suporte afetivo à prole, embora as tarefas domésticas e de cuidado físico com as crianças ainda causem certo estranhamento. Ressalta-se que as práticas parentais se alteram em função da idade dos filhos, a fim de se adaptar às novas habilidades e necessidades infantis, em cada estágio do seu ciclo vital (Minuchin, 1982). De modo que, a acessibilidade do pai, mostra-se mais elevada com relação às crianças de maior idade, visto que nesta fase encontra mais oportunidades de interação, pois a criança é menos dependente da díade mãe-criança, o que a predispõe para outras relações (Bossardi, Bueno \& Vieira, 2015).

Deve-se considerar, também, que nas sociedades ocidentais, as funções parentais assumidas, por pais e mães, têm sido compreendidas como qualitativamente diferentes e complementares para o desenvolvimento infantil, proporcionando o desenvolvimento de capacidades diferentes na criança (Paquette, 2004; Bueno, Gomes, \& Crepaldi, 2015). Estudos apontam que o pai em contato com a criança se ocupa mais de atividades que envolvem brincadeiras lúdicas e físicas, como jogos de lutas e exploração do ambiente, que encorajam a criança a correr riscos enquanto garante sua segurança e propicia o desenvolvimento de autonomia, confiança e segurança (Paquette, 2004; Dumont \& Paquette, 2012; Bossardi, Bueno \& Vieira, 2015).

Além disso, a figura paterna ganha destaque ao se pensar o desenvolvimento cognitivo e comportamental das crianças, uma vez que a literatura registra que quando o pai se encontra ativo nos cuidados dos filhos, este fato favorece que a criança apresente melhor desenvolvimento do aspecto intelectual (Bueno, Gomes, \& Crepaldi, 2015). Assim como, o pai é considerado fundamental para a internalização de regras, limites e conceitos, de certo e errado, por parte da criança. De modo que, uma adequada interação entre pai e filho contribui positivamente para maior competência e habilidades sociais da criança e baixo registro de 
problemas externalizantes como, dificuldade de controlar impulsos, hiperatividade, agressividade e presença de raiva e delinquência (Cabrera, et al., 2000; Paquette, 2004).

Para pensar a paternidade em diferentes contextos familiares e sociais, parte-se do princípio de que as possibilidades de interação entre pais e filhos tornam-se mais complexas e desafiantes, a fim de garantir o melhor desenvolvimento das crianças. Historicamente, com a Lei do Divórcio, em 1977, o casamento deixou de ser um pacto de indissolubilidade e refletiu na multiplicidade de arranjos familiares, reconhecidos socialmente, como a família recasada, monoparental e mais recentemente a homoafetiva. Configurações familiares estas que incluem também a paternidade constituída mediante adoção e métodos de reprodução assistida, esta última refletindo os avanços da tecnologia biomédica.

Em geral, os pesquisadores alertam que em casos de separação conjugal, culturalmente, o pai acaba se distanciando do convívio familiar e, muitas vezes, estremecendo a relação com os filhos (Brito, Cardoso, \& Oliveira, 2010; Arpini, Cúnico, \& Alves, 2016). Por outro lado, os estudos têm reafirmado, de modo consistente, a relevância de preservar-se a relação pai e filhos após a separação conjugal (McGoldrick \& Shibusawa, 2016). No entanto, pouco se conhece acerca das (re)definições das funções paternas em outras estruturas familiares.

Além do mais, o desempenho da paternidade está inter-relacionado com os diferentes sistemas ecológicos em que a família está inserida (Bronfenbrenner, 2005). Nesse sentido, a análise da paternidade deve envolver condições internas e externas ao sistema, considerando que o contexto também é produtor de significados. Afinal, as funções paternas são construídas culturalmente, assim como a expectativa frente as atividades a serem desempenhadas. Nesse sentido, o valor atribuído ao trabalho pelos homens/pais é reflexo de como este fenômeno é desenhado socialmente, em que a identidade paterna se encontra ancorada em padrões que produzem a equivalência entre ser homem e provedor (Freitas, Coelho, \& Silva, 2007). Do mesmo modo, a naturalização da mulher como cuidadora justifica-se por uma construção histórica de funções sociais e da estrutura familiar.

No que tange a transição para a paternidade, uma série de adaptações psicológicas e sociais são exigidas aos futuros pais. A gestação, por sua vez, pode ser compreendida como uma etapa de preparação e elaboração de sentimentos a respeito das novas funções a ser assumidas no ciclo de vida familiar. Para os homens, a formação de vínculo com o bebê costuma ser mais lenta, tornando-se mais concreta após o nascimento da criança e consolidando-se ao 
longo do desenvolvimento desta (Piccinini, et al., 2004). De qualquer modo, Freitas, Coelho e Silva (2007) destacam que o fato de o pai estar próximo durante o período gestacional favorece a construção de vínculos afetivos pai-bebê desde então e o melhor desenvolvimento da paternidade e do laço pai-filho posteriormente. Nesse cenário, o momento do parto, quando acompanhado pelo pai, também tem o potencial de promover efeitos positivos nas relações familiares, em especial, no relacionamento pai-bebê (Perdomini \& Bonilha, 2011). No entanto, por vezes, a participação paterna nas etapas do ciclo gravídico-puerperal ainda é desvalorizada. Por consequência, o parto, o processo de amamentação e os primeiros cuidados com a criança ainda tendem a ser vistos como algo particularmente feminino, e, apesar dos avanços, a participação do pai ainda recebe pouco incentivo e esclarecimento por parte da instituição de saúde, programas sociais e leis trabalhistas.

Nesse sentido, a consciência de maior participação na vida dos filhos, pode encontrar fatores que promovam ou impeçam tal envolvimento. Entre os estudos analisados, a idade dos pais não se mostrou um fator decisivo para o envolvimento paterno. Entretanto, a literatura sobre a parentalidade adolescente indica que jovens pais podem enfrentar problemas adicionais em função das demandas do estágio desenvolvimental em que se encontram, como a imaturidade psicológica e a falta de condições estruturais para lidar com a situação (Lewandowski, Antoni, Koller, \& Piccinini, 2002). De modo semelhante, as características de personalidade dos pais, ou seja, o modo como se comportam, embora tenham impacto na prestação de cuidados aos filhos, não se configuram uma influência central, o que sinaliza para a necessidade de novas investigações.

Em contrapartida, o relacionamento com a mãe da criança pode gerar variações na participação paterna na vida dos filhos. Nesse sentido, estudos reforçam que a qualidade do relacionamento conjugal é considerada um bom preditor para o engajamento paterno, enquanto altos índices de conflito conjugal implicam em baixos níveis de interação entre a díade paicriança (Lindsey, Caldera, \& Tankersley, 2009; Bolze, 2011). Destaca-se, também, o trabalho dos pais com grande poder de influência sobre o relacionamento com os filhos. Os pais com ampla jornada de trabalho fora do lar podem encontrar dificuldades em conciliar o tempo dedicado aos filhos (Souza \& Benetti, 2008). Todavia, os estudos reforçam o quão importante é para construção social da paternidade manter um vínculo estável de trabalho. No âmbito da organização social do trabalho, o suporte a participação masculina, na criação dos filhos, ainda 
se mostra uma utópica, quando na verdade as famílias se beneficiariam de jornadas mais flexíveis. Situação como aprisionamento dos pais e reconhecimento tardio da paternidade também geram importantes reflexões, visto que produzem impactos nas relações familiares e fragilizam a vida afetiva, uma vez que pode ser difícil para criança superar barreiras para ter contato com pai.

No que tange as concepções em torno da paternidade, ao investigar os sentimentos que os pais nutrem pela paternidade, destaca-se a satisfação e a proximidade em relação aos filhos, tanto emocionalmente quanto fisicamente. Sendo que a disposição emocional para se envolver com a paternidade, apresenta-se como motor da participação mais presente na vida dos filhos (Krob, Piccinini, \& Silva, 2009). Também se observou que os pais exerciam suas funções com base em modelos de paternidade que tiveram na infância, fosse essa uma referência positiva ou negativa (Gabriel \& Dias, 2011). Nesse sentido, os resultados da literatura indicam que os homens mais inclinados a se envolver ativamente na relação com a criança são aqueles com uma imagem positiva do próprio pai na infância (Cabrera, et al. 2000). Já na perspectiva das mães, os estudos reforçam que há uma lacuna em relação as funções paternas ideais e o que os homens realmente desempenham. Talvez, isso possa ser explicado pelo momento de transição vivenciado pelas famílias, em especial na conceitualização da paternidade. De modo gradual as mudanças devem ser incorporadas cultural e socialmente, apontando para a produção de novos modelos de paternidade.

Novamente, ressalta-se que há especificidades no modo como pais e mães investem nos filhos. Nesse sentido, umas das expectativas direcionadas a figura que ocupa a posição social de pai é que esta desempenhe a abertura ao mundo à criança (Dumont \& Paquette, 2012), ou seja, incentive a criança a explorar o ambiente a sua volta. Assim como na concepção de pessoas sem filhos, a própria Teoria da Relação de Ativação questiona-se que a frequência de brincadeiras turbulentas, entre elas a de luta, é maior entre pai-filho do que com a menina. O que reforça que este é um tópico de interesse para ser mais explorado, afinal, se o homem ativa mais os filhos meninos, a mãe seria a responsável por exercer a relação de ativação com a menina?

No que corresponde às situações de hospitalização e necessidades especiais dos filhos, os estudos sinalizam para a reorganização familiar frente a esses fatores, em especial, para o fato de que o pai também sofre com o impacto de situações graves que acometem as crianças. 
Estudos nessa área se fazem importante em torno do elevado potencial estressor presente no adoecimento de um membro familiar, o que exige uma preparação da equipe de saúde e o acolhimento da família e sua rede, a fim de garantir uma atenção singular para as vivências de cada família e para todos os membros envolvidos, incluindo o pai.

\section{Considerações Finais}

Entende-se que as investigações científicas sobre essa temática e o reconhecimento da sua importância para o desenvolvimento infantil ainda são recentes. Tal evidência pode servir como incentivo para novas pesquisas, uma vez que, se observa uma relação positiva entre os níveis de envolvimento paterno e o desenvolvimento satisfatório das crianças. A presente revisão da literatura, ao visar uma sistematização do conhecimento disponível na área, apresenta relevância social ao atentar para complexidade dos fatores que perpassam a paternidade e as relações estabelecidas com as crianças. Além disso, pode contribuir para visibilidade da função paterna no sistema familiar, bem como para consolidação de políticas públicas que reconheçam a importância do pai para o desenvolvimento familiar, em especial, dos filhos. No mais, estudos com tal caráter são elementares para o progresso do conhecimento científico, ao revelar perspectivas segundo as quais o fenômeno vem sendo analisado, bem como, estão comprometidos com práticas profissionais mais conectadas com a realidade das famílias.

Ademais, do ponto de vista sistêmico, mudanças paradigmáticas estão acontecendo na dinâmica das famílias, em especial na relação pai-filhos. Contudo, alterações desta ordem exigem tempo e reflexão, para se acomodarem socialmente e serem reforçadas, como um novo valor cultural, diante do fenômeno da paternidade. Por isso, frente a um momento de transição, por vezes, a expectativa dos homens, de maior comprometimento com os filhos, encontra entraves em políticas públicas e aspectos culturais extremamente arraigados.

Destaca-se que, diante do panorama científico apresentado, percebe-se a necessidade de ampliar o foco das investigações e das discussões das pesquisas brasileiras acerca das relações paterno-filiais em configurações familiares não tradicionais, como as famílias recasadas, que estão se tornando cada vez mais recorrente. Assim como, sinaliza-se para a importância de se atentar para programas de intervenção psico-educativos direcionados aos homens e às práticas parentais paternas, tendo em vista os benefícios que poderiam trazer para as relações familiares. 
Recomenda-se que as produções explorem o comportamento paterno em diferentes faixas etárias das crianças, e em especial, com caráter longitudinal, o que pode enriquecer as compreensões a respeito do desenvolvimento de relações pai-criança ao longo do ciclo evolutivo.

O presente trabalho foi realizado com apoio da Coordenação de Aperfeiçoamento de Pessoal de Nível Superior - Brasil (CAPES) - Código de Financiamento 001.

\section{REFERÊNCIAS}

Afonseca, S., Martins, A., \& Pires, V. (2011). Influência da personalidade do pai na participação da prestação de cuidados ao bebê. Psicólogo informação, 15, 13-38. Recuperado de http://pepsic.bvsalud.org/pdf/psicoinfo/v15n15/v15n15a02.pdf

Arpini, D. M., Cúnico, S. D., \& Alves, A. P. (2016). Paternidade: o ponto de vista de profissionais que atuam em varas de família. Pensando Famílias, 20(1), 29-42. Recuperado de http://pepsic.bvsalud.org/pdf/penf/v20n1/v20n1a03.pdf

Backes, M. S., Becker, A. P. S., Crepaldi, M. A., \& Vieira, M. L. (2018). A paternidade e fatores associados ao envolvimento paterno. Nova perspectiva sistêmica, 61, 100-119. Recuperado de http://pepsic.bvsalud.org/pdf/nps/v27n61/v27n61a06.pdf

Bardin, L. (2006). Análise de conteúdo (L. de A. Rego, \& A. Pinheiro, Trads.). Lisboa: Edições 70.

Bolze, S. D. A. (2011). A relação entre engajamento paterno e qualidade de relacionamento conjugal de pais de crianças de 4 a 6 anos. Dissertação de Mestrado, Programa de PósGraduação em Psicologia da Universidade Federal de Santa Catarina, Florianópolis, SC.

Bossardi, C. N., Bueno, R. K., \& Vieira, M. L. (2015). Interação do pai com seus filhos e filhas. In E. R. Goetz \& M. L. Vieira (Eds.), Novo pai: Recursos, desafios e possibilidades (pp. 77-94). Curitiba: Juruá.

Bossardi, C. N., \& Vieira, M. L. (2015) Ser mãe e ser pai: integração de fatores biológicos e culturais. In: E. R. Goetz, M. L. Vieira, (Orgs). Novo pai: percursos, desafios e possibilidades (pp 15-30). Curitiba: Juruá.

Brito, L. M. T., Cardoso, A. R., \& Oliveira, J. D. G. (2010). Debates entre pais e mães divorciados: um trabalho com grupos. Psicologia: Ciência e Profissão, 30(4), 810-823. Recuperado de http://pepsic.bvsalud.org/pdf/pcp/v30n4/v30n4a11.pdf

Bronfenbrenner, U. (2005). Making human beings human: bioecological perspectives on human development. Thousand Oaks: Sage. 
Bueno, R. K., Vieira, M. L., \& Crepaldi, M. A. (2016). Paternidade no contexto da adoção. Pensando Famílias, 20(1), 57-67. Recuperado de http://pepsic.bvsalud.org/pdf/penf/v20n1/v20n1a05.pdf

Bueno, R. K., Gomes, L. B., \& Crepaldi, M. A. (2015). A importância do pai no desenvolvimento da criança. In E. R. Goetz \& M. L. Vieira (Eds.), Novo pai: Recursos, desafios e possibilidades (pp. 95-108). Curitiba: Juruá.

Bustamante, V. (2005). Ser pai no subúrbio ferroviário de Salvador: um estudo de caso com homens de camadas populares. Psicologia em Estudo, 10(3), 393-402. Recuperado de http://www.scielo.br/pdf/pe/v10n3/v10n3a06

Cabrera, N. J., Tamis-LeMonda, C. S., Bradley, R. H., Hofferth, S., \& Lamb, M. E. (2000). Fatherhood in the Twenty-First Century. Child Development, 71(1), 127-136.

Canho, P. G. M., Neme, C. M. B., \& Yamada, M. O. (2006). A vivência do pai no processo de reabilitação da criança com deficiência auditiva. Estudos de Psicologia, 23(3), 261-269. Recuperado de http://www.scielo.br/pdf/estpsi/v23n3/v23n3a05.pdf

Castoldi, L., Gonçalves, T. R., \& Lopes, R. C. L. (2014). Envolvimento paterno da gestação ao primeiro ano de vida do bebê. Psicologia em Estudo, 19(2), 247-259. Recuperado de http://www.scielo.br/pdf/pe/v19n2/08.pdf

Cherer, E. Q., Ferrari, A. G., \& Piccinini, C. A. (2018). Tornar-se pai: a paternidade como inscrição subjetiva da finitude. Psicologia Teoria e Pesquisa, 34, 1-11. Recuperado de http://www.scielo.br/pdf/ptp/v34/1806-3446-ptp-34-e34433.pdf

Cia, F., D’Affonseca, S. M, \& Barham, E. J. (2004). A relação entre o envolvimento paterno e o desempenho acadêmico dos filhos. Paidéia, 14(29), 277-286. Recuperado de http://www.scielo.br/pdf/paideia/v14n29/04.pdf

Cia, F., \& Barham, E. J. (2006). Influências das condições de trabalho do pai sobre o relacionamento pai-filho. Psico-USF, 11(2), 257-264. Recuperado de http://pepsic.bvsalud.org/pdf/psicousf/v11n2/v11n2a14.pdf

Cia, F., \& Barham, E. J. (2009). O envolvimento paterno e o desenvolvimento social de crianças iniciando as atividades escolares. Psicologia em Estudo, 14(1), 67-74. Recuperado de http://www.scielo.br/pdf/pe/v14n1/a09v14n1.pdf

Creswell, J. W. (2007). Projeto de pesquisa: métodos qualitativo, quantitativo e misto ( ${ }^{\text {rd }}$ ed.). Porto Alegre: Artmed.

Cruz, T. A. R., Santos, E. M. S., Silva, F. C., Reis, M. C. S., \& Silva, A. C. D. (2019). Perfil sociodemográfico e participação paterna nos cuidados diários das crianças com microcefalia. Cadernos Brasileiros de Terapia Ocupacional, Ahead of Print. Recuperado de http://www.scielo.br/pdf/cadbto/2019nahead/2526-8910-cadbto-25268910ctoAO1830.pdf 
Cúnico, S. D., Arpini, D. M., \& Cantele, J. (2013). A impossibilidade no exercício da paternidade: algumas reflexões. Psicologia em Revista, 19(3), 353-370. Recuperado de http://pepsic.bvsalud.org/pdf/per/v19n3/v19n3a03.pdf

Cúnico, S. D., \& Arpini, D. M. (2014). Não basta gerar, tem que participar? Um estudo sobre a ausência paterna. Psicologia: Ciência e Profissão, 34(1), 226-241. Recuperado de http://www.scielo.br/pdf/pcp/v34n1/v34n1a16.pdf

Denardi, A. T., \& Bottoli, C. (2017). E quando não é a mãe? A paternidade diante da monoparentalidade. Barbarói, 49, 120-146. Recuperado de https://online.unisc.br/seer/index.php/barbaroi/article/view/5305/6908

Falceto, O. G., Fernandes, C. L., Baratojo, C., \& Giugliani, E. R. J. (2008). Fatores associados ao envolvimento do pai nos cuidados do lactente. Revista de Saúde Pública, 42(6), 10341040. Recuperado de http://www.scielo.br/pdf/rsp/v42n6/6315.pdf

Freitas, L. M. A., \& Alvarenga, P. (2016). Interação pai-criança e problemas externalizantes na infância. Psico, 47(4), 279-287. Recuperado de http://pepsic.bvsalud.org/pdf/psico/v47n4/04.pdf

Freitas, W. M. F., Coelho, E. A. C., \& Silva, A. T. M. C. (2007). Sentir-se pai: a vivência masculina sob o olhar de gênero. Cadernos de Saúde Pública, 23(1), 137-145. Recuperado de http://www.scielo.br/pdf/csp/v23n1/14.pdf

Gabriel, M. R., \& Dias, A. C. G. (2011). Percepções sobre a paternidade: descrevendo a si mesmo e o próprio pai como pai. Estudos de Psicologia, 16(3), 253-261. Recuperado de http://www.scielo.br/pdf/epsic/v16n3/07.pdf

Gabriel, M. R., Silva, M. R., Portugal, P., \& Piccinini, C. A. (2015). Depressão pós-parto maternal e o envolvimento paterno no primeiro ano do bebê. Aletheia. 46, 5065. Recuperado de http://pepsic.bvsalud.org/pdf/aletheia/n46/n46a05.pdf

Gabriel, M. R., Polli, R. G., Dall’Agnol, L. F., Tudge, J., \& Piccinini, C. A. (2016). Envolvimento paterno aos 24 meses de vida da criança. Psicologia: Teoria e Pesquisa, 33, 1-10. Recuperado de http://www.scielo.br/pdf/ptp/v33/1806-3446-ptp-33-e33410.pdf

Gabriel, M. R., \& Lopes, R. C. S. (2016). Transformações no envolvimento paterno ao longo dos seis primeiros meses do bebê na creche. Psicologia: Teoria e Pesquisa, 32(3), 1-10. Recuperado de http://www.scielo.br/pdf/ptp/v32n3/1806-3446-ptp-32-03-e32321.pdf

Gonçalves, T. R., Guimarães, L. E., Silva, M. R., Lopes, R. C. S., \& Piccinini, C. A. (2012). Experiência da paternidade aos três meses do bebê. Psicologia: Reflexão e Crítica, 26(3), 599-608. Recuperado de http://www.scielo.br/pdf/prc/v26n3/v26n3a20.pdf

Gomes, L. B., Crepaldi, M. A., \& Brigas, M. (2013). O engajamento paterno como fator de regulação da agressividade em pré-escolares. Paidéia, 23(54), 21-29. Recuperado de http://www.scielo.br/pdf/paideia/v23n54/0103-863X-paideia-23-54-00021.pdf 
Haslinger, C., \& Bottoli, C. (2017). Tornar-se pai: as implicações da reprodução humana assistida para a paternidade. Barbarói, 49, 94-119. Recuperado de https://online.unisc.br/seer/index.php/barbaroi/article/view/6020/6907

Henn, C. G., \& Piccinini, C. A. (2010). A experiência da paternidade e o envolvimento paterno no contexto de Síndrome de Down. Psicologia: Teoria e Pesquisa, 26(4), 623-631. Recuperado de http://www.scielo.br/pdf/ptp/v26n4/06.pdf

Jager, M. E., \& Bottoli, C. (2011). Paternidade: vivência do primeiro filho e mudanças familiares. Psicologia: Teoria e Prática, 13(1), 141-153. Recuperado de http://pepsic.bvsalud.org/pdf/ptp/v13n1/v13n1a11.pdf

Krob, A. D., Piccinini, C. A., \& Silva, M. R. (2009). A transição para a paternidade da gestação ao segundo mês de vida do bebê. Psicologia USP, 20(2), 269-291. Recuperado de http://pepsic.bvsalud.org/pdf/psicousp/v20n2/v20n2a08.pdf

Lamb, M. (2000). The history of research on father involvement: an overview In H. E. Peters, G. W. Peterson, S. K. Steinmetz \& R. D. Day (Eds), Fatherhood: research interventions and polices. The USA: Haworth Press.

Lamb, M., Pleck, J. H., Charnov, E. L., \& Levine, J. A. (1985). Paternal behavior in humans. American Zoologist, (25), 883-894.

Ledel, K. V., Razera, J., Haack, K. R., \& Falcke, D. (2018). Pais encarcerados: a percepção de mães e crianças sobre a relação pais-filhos. Pensando Famílias, 22(1), 104-117. Recuperado de http://pepsic.bvsalud.org/pdf/penf/v22n1/v22n1a09.pdf

Lewandowski, D. C., Antoni, C., Koller, S. H., \& Piccinini, C. A. (2002). Paternidade na adolescência e os fatores de risco e de proteção para a violência na interação pai-criança. Interações, 13(7), 77-100. Recuperado de http://pepsic.bvsalud.org/pdf/inter/v7n13/v7n13a06.pdf

Lewandowski, D. C., \& Piccinini, C. A. (2002). A interação pai-bebê entre pais adolescentes e adultos. Psicologia: Reflexão e Crítica, 15(2), 413-424. Recuperado de http://www.scielo.br/pdf/prc/v15n2/14364.pdf

Lindsey, E. W., Caldera, Y. M., \& Tankersley, L. (2009). Marital conflict and the quality of young children's peer play behavior: the mediating and moderating role of parent-child emotional reciprocity and attachment security. Journal of Family Psychology, 23(2), 130145.

McGoldrick, M., \& Shibusawa, T. (2016). O ciclo vital familiar. In F. Walsh (Org.), Processos normativos da família: diversidade e complexidade, (4ed.) Porto Alegre: Artmed.

Mendes, K. D. S., Silveira, R. C. C. P., \& Galvão, C. M. (2008). Revisão integrativa: método de pesquisa para a incorporação de evidências na saúde e na enfermagem. Texto \& Contexto Enfermagem, 17(4), 758-764. Recuperado de http://www.scielo.br/pdf/tce/v17n4/18.pdf 
Minuchin, S. (1982). Famílias: funcionamento e tratamento. Porto Alegre: Artmed.

Oliveira, E. M. F., \& Brito, R. S. (2009). Ações de cuidado desempenhadas pelo pai no puerpério. Escola Anna Nery, 13(3), 595-601. Recuperado de http://www.scielo.br/pdf/ean/v13n3/v13n3a20.pdf

Oliveira, A. G., \& Silva, R. R. (2011). Pai contemporâneo: Diálogos entre pesquisadores brasileiros no período de 1998 a 2008. Psicologia Argumento, 29(66),353-360. Recuperado de https://periodicos.pucpr.br/index.php/psicologiaargumento/article/view/20297/19569

Oliveira, A. G., \& Silva, R. R. (2012). Parto também é assunto de homens: uma pesquisa clínico-qualitativa sobre a percepção dos pais acerca de suas reações psicológicas durante o parto. Interação em Psicologia, 16(1), 113-123. Recuperado de https://revistas.ufpr.br/psicologia/article/view/22970/19738

Palmeira, H. M., \& Scorsolini-Comin, F. (2018). Reconhecimento tardio de paternidade e suas repercussões no desenvolvimento dos filhos. Vínculo, 15(2), 1-26. Recuperado de http://pepsic.bvsalud.org/pdf/vinculo/v15n2/v15n2a02.pdf

Paquette, D. (2004). Theorizing the Father-Child relationship: mechanisms and development outcomes. Human Development, 47, 193-219.

Dumont, C., \& Paquette, D. (2012). What about the child's tie to the father? A new insight into fathering, father-child attachment, children's socio-emotional development and the activation relationship. Early Child Development and Care, 183, 1-17.

Paraventi, L., Bittencourt, I. G., Schulz, M. J. L. C., Souza, C. D., Bueno, R. K., \& Vieira, M. L. (2017). A percepção de pessoas sem filhos sobre a função paterna de abertura ao mundo. Psico, 48(1), 1-11. Recuperado de http://revistaseletronicas.pucrs.br/revistapsico/ojs/index.php/revistapsico/article/view/240 57/pdf

Perdomini, F. R. I., \& Bonilha, A. L. L. (2011). A participação do pai como acompanhante da mulher no parto. Texto e Contexto Enfermagem, 20, 445-452. Recuperado de http://www.scielo.br/pdf/tce/v20n3/04.pdf

Piccinini, C. A., Silva, M. R., Gonçalves, T. R, Lopes, R. C. S., \& Tudge, J. (2004). O envolvimento paterno durante a gestação. Psicologia: Reflexão e Crítica, 17(3), 303-314. Recuperado de http://www.scielo.br/pdf/prc/v17n3/a03v17n3.pdf

Piccinini, C. A., Lewandowski, D. C., Gomes, A. G., Lindenmeyer, D., \& Lopes, R. S. (2009). Expectativas e sentimentos de pais em relação ao bebê durante a gestação. Estudos de Psicologia, 26(3), 373-382. Recuperado de http://www.scielo.br/pdf/estpsi/v26n3/v26n3a10.pdf

Piccinini, C. A., Silva, M. R., Gonçalves, T. R, Lopes, R. C. S., \& Tudge, J. (2012). Envolvimento paterno aos três meses de vida do bebê. Psicologia: Teoria e Pesquisa, 28(3), 303-314. Recuperado de http://www.scielo.br/pdf/ptp/v28n3/a06v28n3.pdf 
Pontes, C. M., Alexandrino, A. C., \& Osório, M. M. (2008). Participação do pai no processo de amamentação: vivências, conhecimentos, comportamentos e sentimentos. Jornal de Pediatria, 84(4), 357-364. Recuperado de http://www.scielo.br/pdf/jped/v84n4/v84n4a12.pdf

Polli, R. G., Gabriel, M. R., Piccinini, C. A., \& Lopes, R. C. S. (2016). Envolvimento paterno aos 12 meses de vida do bebê. Psico, 47(3), 198-208. Recuperado de http://pepsic.bvsalud.org/pdf/psico/v47n3/04.pdf

Prado, A. B., Piovanotti, M. R. A., \& Vieira, M. L. (2007). Concepções de pais e mães sobre comportamento paterno real e ideal. Psicologia em Estudo, 12(1), 41-50. Recuperado de http://www.scielo.br/pdf/\%0D/pe/v12n1/v12n1a05.pdf

Romanelli, G. (2004). Paternidade em famílias de camadas médias. Estudos e Pesquisas em Psicologia, 3(2). Recuperado de http://pepsic.bvsalud.org/pdf/epp/v3n2/v3n2a06.pdf

Santos, C. V. M., \& Antúnez, A. E. A. (2018). Paternidade afetivamente inscrita: modalidades de interação na relação pai-bebê. Arquivos Brasileiros de Psicologia, 70(1), 224-238. Recuperado de http://pepsic.bvsalud.org/pdf/arbp/v70n1/16.pdf

Scaglia, A. P., Mishima-Gomes, F. K. T., \& Barbieri, V. (2018). Paternidade em diferentes configurações familiares e o desenvolvimento emocional da filha. Psico, 23(2), 267-278. Recuperado de http://www.scielo.br/pdf/pusf/v23n2/2175-3563-pusf-23-02-267.pdf

Seabra, K. C., \& Seidl-de-Moura, M. L. (2011). Cuidados paternos nos três anos de vida de seus filhos: um estudo longitudinal. Interação em Psicologia, 15(2), 135-147. Recuperado de https://revistas.ufpr.br/psicologia/article/view/17330

Silva, N. C. B., \& Aiello, A. L. R. (2009). Análise descritiva do pai da criança com deficiência mental. Estudos de Psicologia, 26(4), 493-503. Recuperado de http://www.scielo.br/pdf/estpsi/v26n4/10.pdf

Silva, M. R., \& Piccinini, C. A. (2007). Sentimentos sobre a paternidade e o envolvimento paterno: um estudo qualitativo. Estudos de Psicologia, 24(4), 561-573. Recuperado de http://www.scielo.br/pdf/estpsi/v24n4/v24n4a15.pdf

Silva, M. R. S., Bueno, M. E. N., \& Ribeiro, J. P. (2014) A percepção dos pais frente ao seu envolvimento nas atividades com o(s) filho(s). Revista Gaúcha de Enfermagem, 35(1), 1421. Recuperado de http://www.scielo.br/pdf/rgenf/v35n1/pt_1983-1447-rgenf-35-0100014.pdf

Souza, C. L. P., \& Benetti, S. P. C. (2009). Paternidade contemporânea: levantamento da produção acadêmica no período de 2000 a 2007. Paidéia, 19(42), 97-106. Recuperado de http://www.scielo.br/pdf/paideia/v19n42/12.pdf 
Souza, K. S. M., Smeha, L. N., \& Arend, J. C. (2012). A relação entre pais e filho(s) após a separação conjugal. Barbarói, 38, 7-29. Recuperado de https://online.unisc.br/seer/index.php/barbaroi/article/view/1748/2352

Staudt, A. C. P., \& Wagner, A. (2008). Paternidade em tempos de mudança. Psicologia: Teoria e Prática, 10(I), 174-185. Recuperado de http://pepsic.bvsalud.org/pdf/ptp/v10n1/v10n1a13.pdf

Tronchin, D. M. R., \& Tsunechiro, M. A. (2006). Cuidar e o conviver com o filho prematuro: a experiência do pai. Revista Latino Americana de Enfermagem, $14(1)$, 93-101. Recuperado de http://www.scielo.br/pdf/rlae/v14n1/v14n1a13.pdf

Vieira, M. L., Bossardi, C. N., Gomes, L. B., Bolze, S. D. A., Crepaldi, M. A., \& Piccinini, C. A. (2014). Paternidade no Brasil: revisão sistemática de artigos empíricos. Arquivos Brasileiros de Psicologia, 66(2), 36-52. Recuperado de http://pepsic.bvsalud.org/pdf/arbp/v66n2/04.pdf

Warpechowski, A., \& Mosmann, C. (2012). A experiência da paternidade frente à separação conjugal: sentimentos e percepções. Temas em Psicologia, 20(1), 247-260. Recuperado de http://pepsic.bvsalud.org/pdf/tp/v20n1/v20n1a18.pdf 